Article

\title{
Correlation of the Rates of Solvolysis of $i$-Butyl Fluoroformate and a Consideration of Leaving-Group Effects
}

\section{Yelin Lee ${ }^{1}$, Kyoung-Ho Park ${ }^{1}$, Mi Hye Seong ${ }^{1}$, Jin Burm Kyong ${ }^{1} *$ and Dennis N. Kevill ${ }^{2}$}

1 Department of Chemistry and Applied Chemistry, Hanyang University, Ansan-si, Gyeonggi-do 426-791, Korea; E-Mails: redstar486@ hanyang.ac.kr (Y.L.); piroho@hanyang.ac.kr (K.-H.P.); tpdlqk85@hanmail.net (M.H.S.)

2 Department of Chemistry and Biochemistry, Northern Illinois University, DeKalb, IL 60115-2862, USA; E-Mail: dkevill@niu.edu

* Author to whom correspondence should be addressed; E-Mail:jbkyong@ hanyang.ac.kr; Tel.:+82-31-400-5492; Fax: +82-31-400-5457.

Received: 9 September 2011; in revised form: 21 October 2011 / Accepted: 31 October 2011 / Published: 10 November 2011

\begin{abstract}
The specific rates of solvolysis of isobutyl fluoroformate (1) have been measured at $40.0{ }^{\circ} \mathrm{C}$ in 22 pure and binary solvents. These results correlated well with the extended Grunwald-Winstein (G-W) equation, which incorporated the $N_{\mathrm{T}}$ solvent nucleophilicity scale and the $Y_{\mathrm{Cl}}$ solvent ionizing power scale. The sensitivities ( $l$ and $m$-values) to changes in solvent nucleophilicity and solvent ionizing power, and the $k_{F} / k_{C l}$ values are very similar to those observed previously for solvolyses of $n$-octyl fluoroformate, consistent with the additional step of an addition-elimination pathway being rate-determining. The solvent deuterium isotope effect value $\left(k_{\mathrm{MeOH}} / k_{\mathrm{MeOD}}\right)$ for methanolysis of $\mathbf{1}$ was determined, and for solvolyses in ethanol, methanol, $80 \%$ ethanol, and $70 \%$ TFE, the values of the enthalpy and the entropy of activation for the solvolysis of $\mathbf{1}$ were also determined. The results are compared with those reported earlier for isobutyl chloroformate (2) and other alkyl haloformate esters and mechanistic conclusions are drawn.
\end{abstract}

Keywords: $i$-butyl fluoroformate; Grunwald-Winstein equation; leaving group effect; addition-elimination; solvolysis 


\section{Introduction}

Linear free energy relationship (LFER) analysis with the extended Grunwald-Winstein (G-W) equation (Equation 1) has long been employed as a diagnostic tool for the study of solvent effects on solvolytic reactions $[1,2]$.

$$
\log \left(k / k_{\mathrm{o}}\right)=l N_{\mathrm{T}}+m Y_{\mathrm{Cl}}+c
$$

In Equation 1, $k$ and $k_{o}$ are the specific rates of solvolysis of a substrate in a given solvent and in $80 \%$ ethanol, respectively; $l$ is the sensitivity towards changes in $N_{\mathrm{T}}$, a scale of solvent nucleophilicity based on the specific rates of solvolysis of $S$-methyl-dibenzothiophenium ion [3,4]; $m$ is the sensitivity towards changes in $Y_{\mathrm{Cl}}$ [5-8], a scale of solvent ionizing power based on the specific rates of solvolysis of 1-adamantyl chloride, and $c$ is the intercept.

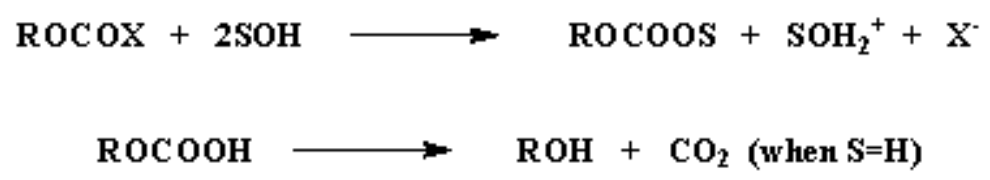

$\mathrm{ROCOOH} \longrightarrow \mathrm{ROH}+\mathrm{CO}_{2}$ (when $\left.\mathrm{S}=\mathrm{H}\right)$

[Addition-Elim ination Mecha nism]

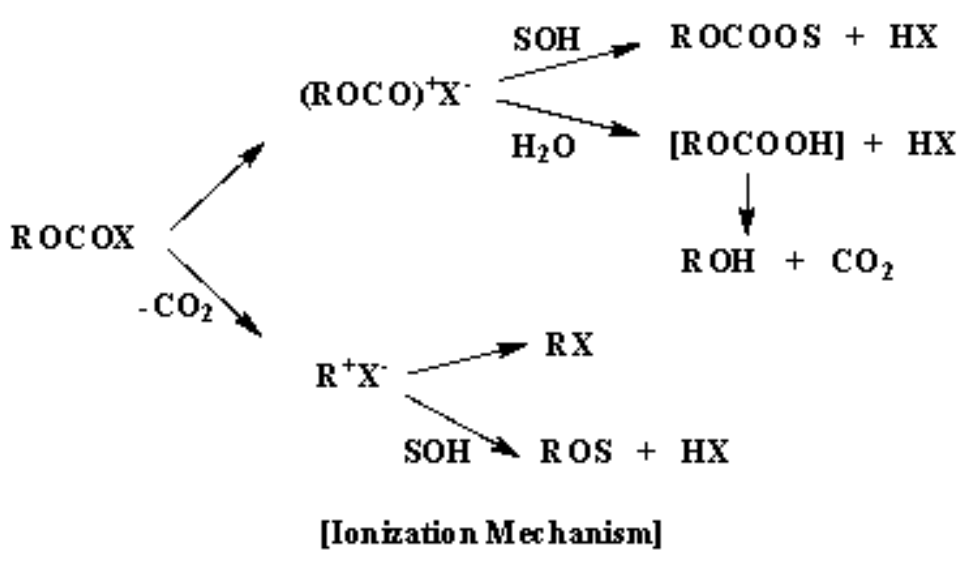

We have previously studied solvolysis reactions of alkyl and aryl haloformate esters concerning the application of the G-W equation [1,9]. In hydroxylic solvents, chloroformates with primary alkyl groups solvolyze with rate-determining attack at the carbonyl carbon (Equation 2). Only in solvents of very low nucleophilicity and very high ionizing power is an ionization mechanism observed (Equation 3) [10-13]. Secondary alkyl chloroformates follow the ionization pathway (Equation 4) in all the mixed solvents except for the more nucleophilic and less ionizing solvents (i.e., in ethanol and methanol and their mixtures with $10 \%$ water) [14]. For tertiary 1-adamantyl chloroformate (1-AdOCOCl) [15], the ionization pathway (Equation 4) was dominant in all the mixed solvents and only in $100 \%$ ethanol was a trace of the mixed carbonate detected.

We have also reported that the solvolyses of primary and secondary alkyl fluoroformates (e.g., methyl (3) [16], ethyl (4) [17], $n$-propyl (5) [18], n-octyl (6) [19], and isopropyl (7) [20], Figure 1) in a wide range of hydroxylic solvents follow an addition-elimination pathway. Solvolyses of $t$-butyl fluoroformate (8, Figure 1) [21] were found to proceed entirely by an ionization pathway (Equation 4), which included the loss of carbon dioxide to give the relatively stable $t$-butyl cation. 
Solvolyses of tertiary 1-adamantyl fluoroformate (9, Figure 1) [22] led to two types of mechanisms, i.e., a bimolecular pathway (Equation 2) and an ionization pathway (Equation 4). Accordingly, in order to extend the kinetic study on the solvolysis of alkyl haloformates to $\mathbf{1}$, we have investigated the solvolysis reactions of $\mathbf{1}$ in a variety of pure and binary aqueous organic solvents using the extended G-W equation (Equation 1). We also report solvolysis studies at three different temperatures in four organic solvents to determine the values of enthalpy $\left(\Delta H^{\ddagger}\right)$ and entropy $\left(\Delta S^{\ddagger}\right)$ of activation and the solvent deuterium isotope effect for methanolysis $\left(k_{\mathrm{MeOH}} / k_{\mathrm{MeOD}}\right)$. These analyses were combined with a consideration of leaving group effects, by comparison with the values for isobutyl chloroformate (2) solvolyses [13], to arrive at a reasonable mechanism.

Figure 1. Molecular structures of isobutyl fluoroformate (1), isobutyl chloroformate (2), methyl fluoroformate (3), ethyl fluoroformate (4), n-propyl fluoroformate (5), n-octyl fluoroformate (6), isopropyl fluoroformate (7), tertiary butyl fluoroformate (8), and tertiary 1-adamantyl fluoroformate (9).<smiles>CC(C)COC(=O)F</smiles>

1<smiles>CC(C)COC(=O)Cl</smiles>

2<smiles>COC(=O)F</smiles>

3<smiles>CCOC(=O)F</smiles>

4<smiles>CCCOC(=O)F</smiles>

5<smiles>CC(C)OC(=O)F</smiles>

7<smiles>CCCCCCCCOC(=O)F</smiles>

6<smiles>O=C(F)OC12CC3CC(CC(C3)C1)C2</smiles>

9

\section{Results and Discussion}

The specific rates of solvolysis of $\mathbf{1}$ at $40.0{ }^{\circ} \mathrm{C}$ are reported in Table 1 . The solvents consisted of ethanol, methanol, binary mixtures of water with ethanol, methanol , 2,2,2-trifluoroethanol (TFE), acetone $\left(\mathrm{Me}_{2} \mathrm{CO}\right), 1,1,1,3,3,3$-hexafluoro-2-propanol (HFIP) and four binary mixtures of TFE and ethanol. The associated $N_{\mathrm{T}}$ and $Y_{\mathrm{Cl}}$ values are also reported in Table 1, together with the solvent deuterium isotope effect values for $\mathbf{1}$ and $\mathbf{2}$ in methanol-d (footnote to Table 1). The solvents studied include the important 2,2,2-trifluoroethanol (TFE)-water binary mixtures. These are important to minimize a multicollinearity which when powerful can invalidate the coefficients obtained by multiple regression analysis using extended forms of the Grunwald-Winstein equation. [23,24]. Specific rates of solvolysis of 1 were determined at four different temperatures in methanol, ethanol, $80 \%$ ethanol, and $70 \%$ TFE, and these values, together with calculated enthalpies and entropies of activation, are 
reported in Table 2 . The obtained $l, m$, and $c$ values, together with the corresponding literature values for solvolyses of other fluoroformate esters are summarized in Table 3.

Table 1. Specific rates of solvolysis of isobutyl fluoroformate (1) ${ }^{a}$ in pure and binary solvents at $40.0^{\circ} \mathrm{C}$ and the $N_{\mathrm{T}}$ and $Y_{\mathrm{Cl}}$ values for the solvents.

\begin{tabular}{cccc}
\hline Solvent $^{b}$ & $\left.\mathbf{1 0}^{\mathbf{4}} \boldsymbol{k} \mathbf{( s}^{\mathbf{- 1}}\right)^{\boldsymbol{c}}$ & $\boldsymbol{N}_{\mathbf{T}}{ }^{d}$ & $\boldsymbol{Y}_{\mathbf{C l}}{ }^{d}$ \\
\hline $100 \% \mathrm{MeOH}{ }^{e}$ & $2.15 \pm 0.02^{g}$ & 0.17 & -1.17 \\
$90 \% \mathrm{MeOH}$ & $15.1 \pm 0.2$ & -0.01 & -0.18 \\
$80 \% \mathrm{MeOH}$ & $42.5 \pm 0.2$ & -0.06 & 0.67 \\
$70 \% \mathrm{MeOH}$ & $77.6 \pm 0.2$ & -0.40 & 1.46 \\
$100 \% \mathrm{EtOH}$ & $0.378 \pm 0.002$ & 0.37 & -2.52 \\
$90 \% \mathrm{EtOH}$ & $6.77 \pm 0.04$ & 0.16 & -0.94 \\
$80 \% \mathrm{EtOH}$ & $14.4 \pm 0.1$ & 0.00 & 0.00 \\
$70 \% \mathrm{EtOH}$ & $24.1 \pm 0.1$ & -0.20 & 0.78 \\
$60 \% \mathrm{EtOH}$ & $35.3 \pm 0.2$ & -0.38 & 1.38 \\
$50 \% \mathrm{EtOH}$ & $70.0 \pm 0.2$ & -0.58 & 2.02 \\
$90 \% \mathrm{Acetone}$ & $0.0923 \pm 0.0002$ & -0.35 & -2.39 \\
$80 \% \mathrm{Acetone}$ & $0.823 \pm 0.001$ & -0.37 & -0.80 \\
$70 \% \mathrm{Acetone}$ & $2.60 \pm 0.01$ & -0.42 & 0.17 \\
$60 \% \mathrm{Acetone}$ & $6.44 \pm 0.03$ & -0.52 & 1.00 \\
$97 \% \mathrm{TFE}$ & $0.00678 \pm 0.00005$ & -3.30 & 2.83 \\
$90 \% \mathrm{TFE}$ & $0.103 \pm 0.003$ & -2.55 & 2.85 \\
$70 \% \mathrm{TFE}$ & $2.33 \pm 0.04$ & -1.98 & 2.96 \\
$50 \% \mathrm{TFE}$ & $8.81 \pm 0.04$ & -1.73 & 3.16 \\
$80 \mathrm{~T}-20 \mathrm{E}^{f}$ & $0.0500 \pm 0.0005$ & -1.76 & 1.89 \\
$60 \mathrm{~T}-40 \mathrm{E}^{f}$ & $0.173 \pm 0.002$ & -0.94 & 0.63 \\
$40 \mathrm{~T}-60 \mathrm{E}^{f}$ & $0.440 \pm 0.002$ & -0.34 & -0.48 \\
$20 \mathrm{~T}-80 \mathrm{E}^{f}$ & $0.598 \pm 0.004$ & 0.08 & -1.42 \\
\hline
\end{tabular}

${ }^{a}$ Substrate concentration is $5.81 \times 10^{-3} \mathrm{~mol} \mathrm{dm}^{-3} ;{ }^{b}$ Volume/volume basis at $25.0{ }^{\circ} \mathrm{C}$, except for TFE- $\mathrm{H}_{2} \mathrm{O}$ mixtures, which are on a weight/weight basis; ${ }^{c}$ The average of all integrated specific rates from duplicate runs, with associated standard deviation; ${ }^{d}$ From references [4] and [6]; ${ }^{e}$ Specific rates of solvolysis of isobutyl chloroformate (2) in $100 \% \mathrm{MeOH}$ and $100 \% \mathrm{MeOD}$ at $40.0{ }^{\circ} \mathrm{C}$ are $(3.27 \pm 0.05)_{\mathrm{MeOH}} \times 10^{-4} \mathrm{~s}^{-1}$ and $(1.64 \pm 0.02)_{\mathrm{MeOD}} \times 10^{-4} \mathrm{~s}^{-1}$, respectively, and the $k_{\mathrm{MeOH}} / k_{\mathrm{MeOD}}$ value of solvolysis of isobutyl chloroformate is $2.00 \pm 0.02 ;{ }^{f}$ T-E are 2,2,2-trifluoroethanol-ethanol mixtures; ${ }^{g}$ Value in MeOD of $0.632 \pm 0.003$, and a solvent deuterium isotope effect $\left(k_{\mathrm{MeOH}} / k_{\mathrm{MeOD}}\right)$ of $3.40 \pm 0.02$. 
Table 2. Specific rates for solvolysis of isobutyl fluoroformate (1) at various temperatures and enthalpies $\left(\Delta H^{\ddagger}, \mathrm{kcal} \cdot \mathrm{mol}^{-1}\right)$ and entropies $\left(\Delta S^{\ddagger}, \mathrm{cal} \cdot \mathrm{mol}^{-1} \cdot \mathrm{K}^{-1}\right)$ of activation.

\begin{tabular}{|c|c|c|c|c|}
\hline Solvent $^{a}$ & $\mathrm{~T},{ }^{\circ} \mathrm{C}$ & $10^{4} k\left(s^{-1}\right)^{b}$ & $\Delta \boldsymbol{H}_{313}^{+}{ }^{c}$ & $\Delta S_{313}^{*}{ }^{c}$ \\
\hline \multirow[t]{4}{*}{$100 \% \mathrm{MeOH}$} & 40.0 & $2.15 \pm 0.02^{d}$ & $9.5 \pm 0.2$ & $-45.2 \pm 0.7$ \\
\hline & 45.0 & $2.80 \pm 0.04$ & & \\
\hline & 50.0 & $3.51 \pm 0.02$ & & \\
\hline & 55.0 & $4.55 \pm 0.02$ & & \\
\hline \multirow[t]{4}{*}{$100 \% \mathrm{EtOH}$} & 40.0 & $0.378 \pm 0.002^{d}$ & $10.5 \pm 0.2$ & $-45.3 \pm 0.8$ \\
\hline & 45.0 & $0.508 \pm 0.002$ & & \\
\hline & 50.0 & $0.671 \pm 0.002$ & & \\
\hline & 55.0 & $0.854 \pm 0.003$ & & \\
\hline \multirow[t]{4}{*}{$80 \% \mathrm{EtOH}$} & 40.0 & $14.4 \pm 0.1^{d}$ & $9.8 \pm 0.5$ & $-40.3 \pm 1.5$ \\
\hline & 45.0 & $19.5 \pm 0.2$ & & \\
\hline & 50.0 & $25.0 \pm 0.2$ & & \\
\hline & 55.0 & $31.0 \pm 0.3$ & & \\
\hline \multirow[t]{4}{*}{$70 \%$ TFE } & 40.0 & $2.33 \pm 0.04^{d}$ & $11.1 \pm 0.4$ & $-39.9 \pm 1.4$ \\
\hline & 45.0 & $3.08 \pm 0.01$ & & \\
\hline & 50.0 & $4.03 \pm 0.04$ & & \\
\hline & 55.0 & $5.54 \pm 0.02$ & & \\
\hline
\end{tabular}

${ }^{a, b}$ See footnotes in Table $1 ;{ }^{c}$ With associated standard error; ${ }^{d}$ From Table 1.

Table 3. Correlations of the specific rates of solvolysis of isobutyl fluoroformate (1) and a comparison with the corresponding values for the solvolyses of isobutyl chloroformate and other fluoroformates using the Grunwald-Winstein equation.

\begin{tabular}{cccccccc}
\hline Substrate & Mech. $^{a}$ & $\mathbf{n}^{\boldsymbol{b}}$ & $\boldsymbol{l}^{\boldsymbol{c}}$ & $\boldsymbol{m}^{\boldsymbol{c}}$ & $\boldsymbol{c}^{\boldsymbol{c}}$ & $\boldsymbol{R}^{\boldsymbol{d}}$ & $\boldsymbol{l} \boldsymbol{m}$ \\
\hline $\mathbf{1}$ & $\mathrm{A}-\mathrm{E}$ & $22^{e}$ & $1.78 \pm 0.13$ & $0.85 \pm 0.10$ & $-0.07 \pm 0.10$ & 0.956 & 2.09 \\
& $\mathrm{~A}-\mathrm{E}$ & $18^{e, f}$ & $1.68 \pm 0.07$ & $0.80 \pm 0.04$ & $0.01 \pm 0.05$ & 0.989 & 2.10 \\
$\mathbf{2}$ & $\mathrm{A}-\mathrm{E}$ & $18^{g}$ & $1.82 \pm 0.15$ & $0.53 \pm 0.05$ & $0.18 \pm 0.07$ & 0.957 & 3.43 \\
$\mathbf{3}$ & $\mathrm{A}-\mathrm{E}$ & $14^{h}$ & $1.33 \pm 0.09$ & $0.73 \pm 0.06$ & $-0.08 \pm 0.08$ & 0.972 & 1.82 \\
$\mathbf{4}$ & $\mathrm{A}-\mathrm{E}$ & $17^{i}$ & $1.34 \pm 0.14$ & $0.77 \pm 0.07$ & $-0.06 \pm 0.10$ & 0.942 & 1.74 \\
$\mathbf{5}$ & $\mathrm{A}-\mathrm{E}$ & $16^{j}$ & $1.72 \pm 0.12$ & $0.91 \pm 0.08$ & $0.05 \pm 0.08$ & 0.970 & 1.89 \\
$\mathbf{6}$ & $\mathrm{A}-\mathrm{E}$ & $19^{k}$ & $1.67 \pm 0.07$ & $0.76 \pm 0.03$ & $-0.08 \pm 0.18$ & 0.988 & 2.20 \\
$\mathbf{7}$ & $\mathrm{A}-\mathrm{E}$ & $20^{l}$ & $1.59 \pm 0.16$ & $0.80 \pm 0.06$ & $0.06 \pm 0.08$ & 0.957 & 1.99 \\
$\mathbf{8}$ & $\mathrm{I}$ & $17^{m}$ & $0.41 \pm 0.05$ & $0.65 \pm 0.03$ & $0.02 \pm 0.04$ & 0.989 & 0.63 \\
$\mathbf{9}$ & $\mathrm{A}-\mathrm{E}$ & $10^{n}$ & $2.78 \pm 0.21$ & $1.01 \pm 0.06$ & $0.09 \pm 0.16$ & 0.987 & 2.78 \\
& $\mathrm{I}$ & $16^{n}$ & $\sim 0$ & $0.70 \pm 0.01$ & $-0.02 \pm 0.05$ & 0.999 & $\sim 0$ \\
\hline
\end{tabular}

\footnotetext{
${ }^{a}$ Addition-elimination (A-E) and ionization (I); ${ }^{b}$ Number of solvent systems included in the correlation;

${ }^{c}$ Using equation 1, with standard errors for $l$ and $m$ values and with standard errors of the estimate accompanying the $c$ values; ${ }^{d}$ Correlation coefficient; ${ }^{e}$ This study; ${ }^{f}$ Omitting the TFE-ethanol solvents; ${ }^{g}$ The solvent systems with omission of the four TFE- $\mathrm{H}_{2} \mathrm{O}$ solvents, reference [13]; ${ }^{h}$ Reference [16]; ${ }^{i}$ Reference [17]; ${ }^{j}$ Reference [18]; ${ }^{k}$ Reference [19]; ${ }^{l}$ Reference [20]; ${ }^{m}$ Reference [21]; ${ }^{n}$ The 26 solvent systems divided into 16 aqueous fluoroalcohol solvents and the remainder (reference [22]).
}

As shown in Table 1, the specific rates for solvolysis of $\mathbf{1}$ increase with increasing water content in all the mixed solvents, indicating that the specific rate is accelerated by solvents with higher ionizing power $\left(Y_{\mathrm{Cl}}\right)$. In contrast, solvolysis of $\mathbf{1}$ proceeds more rapidly with increasing ethanol content in the 
four TFE-ethanol solvents. These phenomena are similar to those previously reported for solvolysis of primary and secondary alkyl fluoroformates in various solvents [16-20], which have been suggested to proceed through an addition-elimination mechanism with the addition step being rate determining. As is the nature of the nucleophilic acyl substitution reactions, the rate of addition to the carbonyl carbon is slower as the steric demands of the alkyl group (i.e., branching at the $\alpha$-carbon) increase, and the rate of the reaction was enhanced as the electron withdrawing ability of the alkoxy group increases the positive charge on the carbonyl carbon (electronic effects) [25]. In Table 4, the order of the specific rate for solvolyses of $\mathbf{1}$ in relation to those previously studied for primary, secondary and tertiary alkyl fluoroformates is shown to be $k_{\mathrm{Me}}>k_{\mathrm{Et}} \approx k_{\mathrm{n}-\mathrm{Pr}} \approx k_{\mathrm{i}-\mathrm{Bu}} \approx k_{\mathrm{n}-\mathrm{Oct}}>k_{\mathrm{i}-\mathrm{Pr}}>k_{\mathrm{t}-\mathrm{Bu}}>k_{1-\mathrm{Ad}}$ in $100 \% \mathrm{MeOH}$, $100 \% \mathrm{EtOH}$, and $80 \% \mathrm{EtOH}$ but not in $70 \%$ TFE [16-22].

Table 4. A comparison of the specific rates $\left(10^{4} k\left(\mathrm{~s}^{-1}\right)\right){ }^{a, b}$ of solvolysis of several alkyl fluoroformates (ROCOF) in pure and binary solvents at $25.0{ }^{\circ} \mathrm{C}$, and the solvent isotope effect values $\left(k_{\mathrm{MeOH}} / k_{\mathrm{MeOD}}\right)$.

\begin{tabular}{|c|c|c|c|c|c|c|c|c|}
\hline Solvent $^{c}$ & methyl $^{e}$ & ethyl $^{f}$ & $n$-propyl ${ }^{g}$ & $i$-butyl ${ }^{h}$ & $n$-octyl ${ }^{i}$ & $i$-propyl ${ }^{j}$ & $t$-butyl ${ }^{k}$ & 1-adamantyl ${ }^{l}$ \\
\hline $100 \% \mathrm{MeOH}$ & $\begin{array}{c}2.47 \\
(5.81)\end{array}$ & $\begin{array}{l}0.836 \\
(2.32)\end{array}$ & $\begin{array}{c}- \\
(2.19)\end{array}$ & $\begin{array}{l}0.952 \\
(2.15)\end{array}$ & 0.853 & 0.217 & $7.43 \times 10^{-2}$ & $2.51 \times 10^{-2}$ \\
\hline $100 \% \mathrm{EtOH}$ & $\begin{array}{l}0.424 \\
(1.09)\end{array}$ & $\begin{array}{c}0.135 \\
(0.394)\end{array}$ & $\begin{array}{c}- \\
(0.437)\end{array}$ & $\begin{array}{c}0.155 \\
(0.378)\end{array}$ & 0.153 & $3.93 \times 10^{-2}$ & $1.31 \times 10^{-2}$ & $2.29 \times 10^{-3}$ \\
\hline $80 \% \mathrm{EtOH}$ & $\begin{array}{c}19.1 \\
(43.6)\end{array}$ & $\begin{array}{c}6.52 \\
(14.3)\end{array}$ & $\begin{array}{c}- \\
(14.0)\end{array}$ & $\begin{array}{c}6.31 \\
(14.4)\end{array}$ & $5.96^{m}$ & 1.71 & 0.616 & 0.150 \\
\hline $70 \% \mathrm{TFE}^{d}$ & $\begin{array}{c}4.75 \\
(10.8)\end{array}$ & $\begin{array}{c}1.23 \\
(3.61)\end{array}$ & $\begin{array}{c}- \\
(2.20)\end{array}$ & $\begin{array}{l}0.895 \\
(2.33)\end{array}$ & $0.430^{m}$ & 0.240 & 6.84 & - \\
\hline$k_{\mathrm{MeOH}} / k_{\mathrm{MeOD}}$ & $3.98^{e}$ & $3.10^{f}$ & $3.32^{g}$ & $3.40^{h}$ & - & $2.53^{j}$ & $1.26^{k}$ & - \\
\hline
\end{tabular}

${ }^{a}$ Values obtained using Arrhenius plots with the specific rates reported at different temperatures; ${ }^{b}$ Values in parentheses represent the specific rates obtained at $40.0{ }^{\circ} \mathrm{C}$; ${ }^{c}$ Unless otherwise indicated, on a volume/volume basis, at $25.0{ }^{\circ} \mathrm{C}$, with the other component water; ${ }^{d}$ Solvent prepared on weight/weight basis; ${ }^{e}$ From reference [16]; ${ }^{f}$ From reference [17]; ${ }^{g}$ From reference [18]; ${ }^{h}$ This study; ${ }^{i}$ From reference [19]; ${ }^{j}$ From reference [20]; ${ }^{k}$ From reference [21]; ${ }^{l} 1$-adamantyl fluoroformate, from reference [22]; ${ }^{m}$ Values at $24.2{ }^{\circ} \mathrm{C}$.

The difference in reactivity of $\mathbf{8}$ and $\mathbf{9}$ has previously been discussed by other workers [5,8]. The rate ratios for $\mathbf{1}, \mathbf{4}, \mathbf{5}$, and $\mathbf{6}$ in $100 \% \mathrm{MeOH}, 100 \% \mathrm{EtOH}$, and $80 \% \mathrm{EtOH}$ (Table 4) being close to unity $\left(k_{\mathrm{ROCOF}} / k_{\mathrm{EtOCOF}}=0.91 \sim 1.15\right)$ suggests that electronic and/or steric influences due to the presence of a branching $\beta$-alkyl group in the alkyl fluoroformates can be neglected. On the other hand, the specific rate of solvolysis of $\mathbf{8}$ in $70 \%$ TFE was somewhat faster than the rates of $\mathbf{1 , 4 , 5 , 6}$ and $\mathbf{7}$. The higher rate ratio $\left(k_{\mathrm{t}-\mathrm{BuOCOF}} / k_{\mathrm{EtOCOF}}=5.6\right)$ in $70 \% \mathrm{TFE}$ relative to $100 \% \mathrm{MeOH}, 100 \% \mathrm{EtOH}$, and $80 \%$ EtOH probably results from solvolysis of $\mathbf{8}$ (via the relatively stable t-butyl cation) being more favored by the electrophilic influence of the relatively acidic TFE than the other alkyl fluoroformates, which are believed to proceed by a bimolecular pathway, i.e., for tertiary alkyl haloformates that undergo solvolysis by an ionization process, an increase in the polarity of the solvent and/or its ion-solvation ability resulted in a significant increase in reaction rate. The specific rate of solvolysis of $\mathbf{8}$, which has been reported to proceed through an ionization pathway, was found to be $4.0 \times 10^{2}$ times faster in $70 \%$ TFE $\left(Y_{\mathrm{Cl}}=2.96\right)$ than in $100 \% \mathrm{EtOH}\left(Y_{\mathrm{Cl}}=-2.52\right)$. This phenomenon occurs because, in the ionization 
pathway, charge is developed and concentrated in the transition state compared with the starting material (Equation 4).

Consideration of leaving group effects in nucleophilic substitution reactions has long been recognized as a useful tool in studying reaction mechanisms [26]. For the ionization pathway, a value of $k_{\mathrm{F}} / k_{\mathrm{Cl}}=1.3 \times 10^{-4}$ was observed for acetyl halide solvolyses [27], and a low value of $k_{\mathrm{F}} / k_{\mathrm{Cl}}=1.20 \times 10^{-5}-3.17 \times 10^{-5}$ was observed for 1-adamantyl haloformate solvolyses [15,22]. Since the carbon-fluoride bond $(\mathrm{C}-\mathrm{F})$ is much stronger than the carbon-chloride bond $(\mathrm{C}-\mathrm{Cl})$, if the carbonhalogen bond is broken in the rate-determining step (ionization pathway), the $k_{\mathrm{F}} / k_{\mathrm{Cl}}$ ratio would be expected to exhibit a significant leaving group effect, $k_{\mathrm{F}} \ll k_{\mathrm{Cl}}$. In contrast, if the addition step is ratedetermining (i.e., bimolecular pathway), values of close to unity, reflecting a large electron deficiency at the carbonyl carbon of the fluoroformate, would be frequently observed, and the bimolecular pathway through a tetrahedral intermediate formed by the rate-determining addition of solvent to the carbonyl carbon would be characterized by $k_{\mathrm{F}} \geq k_{\mathrm{Cl}}$. A previous report concerning the solvolyses of $\mathbf{4 , 5}$, 6 and 7 [17-20], which were believed to solvolyze by an addition-elimination mechanism, found a $k_{\mathrm{F}} / k_{\mathrm{Cl}}$ ratio to be somewhat below unity in ethanol and methanol and slightly greater than unity for solvolyses in mixtures of water with ethanol, methanol, acetone, or TFE (Table 5). For other haloformate esters, $k_{\mathrm{F}} / k_{\mathrm{Cl}}$ ratios of 1.09 to 7.16 for solvolyses in $70 \%$ aqueous acetone at $30.1{ }^{\circ} \mathrm{C}$ have been reported [28]. As mentioned above, for binary solvents, the specific rates for solvolysis of the fluoroformate are somewhat faster, despite the stronger carbon-fluorine bond. As shown in Table 5, the $k_{\mathrm{F}} / k_{\mathrm{Cl}}$ ratios were similar for all the substrates, which have been reported to proceed through a bimolecular pathway. They are smaller for the 1-adamantyl substrates, which presumably proceed through a solvolysis-decomposition reaction (ionization pathway) in ethanol, methanol, and 80\% ethanol.

Table 5. The specific rate ratios $\left(k_{F} / k_{C l}\right)$ of solvolyses of alkyl haloformates in pure and binary solvents at various temperatures.

\begin{tabular}{cccccccc}
\hline Solvent $^{\boldsymbol{a}}$ & methyl $^{\boldsymbol{c}}$ & ethyl $^{\boldsymbol{d}}$ & $\boldsymbol{n}$-propyl & $\boldsymbol{i}^{\boldsymbol{i}}$-butyl & $\boldsymbol{n}^{\boldsymbol{n} \text {-octyl }}{ }^{\boldsymbol{g}}$ & $\boldsymbol{i}_{\text {-propyl }}{ }^{\boldsymbol{h}}$ & 1-adamantyl $^{\boldsymbol{i}}$ \\
\hline $100 \% \mathrm{EtOH}$ & 0.83 & 0.57 & 0.57 & 0.45 & 0.62 & 0.18 & $1.20 \times 10^{-5}$ \\
$80 \% \mathrm{EtOH}$ & 8.28 & 8.74 & 5.62 & 5.43 & 8.09 & 2.11 & $3.17 \times 10^{-5}$ \\
$60 \% \mathrm{EtOH}$ & - & 14.0 & - & 8.43 & 15.1 & 1.79 & - \\
$100 \% \mathrm{MeOH}$ & 1.12 & 0.93 & 0.75 & 0.66 & 0.95 & 0.39 & $1.56 \times 10^{-5}$ \\
$90 \% \mathrm{MeOH}$ & 5.11 & 4.82 & - & 2.42 & - & 1.76 & - \\
$80 \% \mathrm{Me}_{2} \mathrm{CO}$ & 3.71 & 3.90 & $4.24^{j}$ & 2.60 & 2.86 & 0.53 & - \\
$70 \% \mathrm{TFE}^{b}$ & 27.2 & 19.3 & 7.72 & 8.86 & $10.2^{k}$ & 0.067 & - \\
\hline
\end{tabular}

${ }^{a}$ Unless otherwise indicated, on a volume/volume basis, at $25.0{ }^{\circ} \mathrm{C}$, with the other component water;

${ }^{b}$ Solvents prepared on weight/weight basis; ${ }^{c}$ At $40.0{ }^{\circ} \mathrm{C}$ in reference [16]; ${ }^{d}$ At $24.2{ }^{\circ} \mathrm{C}$ in reference [17];

${ }^{e}$ At $40.0{ }^{\circ} \mathrm{C}$ in reference [18]; ${ }^{f}$ At $40.0{ }^{\circ} \mathrm{C}$ in this study; ${ }^{g}$ At $24.2{ }^{\circ} \mathrm{C}$ in reference [19]; ${ }^{h}$ At $40.0{ }^{\circ} \mathrm{C}$ in reference [20];

${ }^{i}$ At $50.0{ }^{\circ} \mathrm{C}$ in reference $[22] ;{ }^{j}$ For $70 \% \mathrm{Me}_{2} \mathrm{CO} ;{ }^{k}$ For $80 \%$ TFE.

The solvent deuterium isotope effect value for methanolysis of $\mathbf{1}$ is of a magnitude usually taken to indicate that nucleophilic attack by a methanol molecule is assisted by general-base catalysis by a second methanol molecule (Table 4) [29-31]. The value $\left(k_{\mathrm{MeOH}} / k_{\mathrm{MeOD}}=3.40\right.$ at $\left.40.0{ }^{\circ} \mathrm{C}\right)$ for $\mathbf{1}$ is slightly larger than for methanolysis of $2\left(k_{\mathrm{MeOH}} / k_{\mathrm{MeOD}}=2.00\right.$ at $\left.40.0{ }^{\circ} \mathrm{C}\right)$, which further supports the proposal that bond formation is more advanced in the transition state for addition to fluoroformate than 
for chloroformate. The solvent deuterium isotope effect has previously been studied for several solvolyses of haloformate esters (Table 4 ). In methanol, the $k_{\mathrm{MeOH}} / k_{\mathrm{MeOD}}$ ratio was in the range of 2.00 to 3.98 for solvolyses of alkyl and aryl haloformates which have been reported to proceed through a bimolecular mechanism [10-13,16-20,32,33]. The $k_{\mathrm{ROH}} / k_{\mathrm{ROD}}$ values for $i$-propyl chloroformate and $\mathbf{8}$ in the range of an ionization mechanism, were somewhat smaller at 1.25 in pure water [34] and 1.26 [21] in methanol, respectively.

For solvolyses in ethanol, methanol, $80 \%$ ethanol, and $70 \%$ TFE, the values of the enthalpy and the entropy of activation for the solvolysis of $\mathbf{1}$ (Table 2) are $9.5 \sim 11.1 \mathrm{kcal} \cdot \mathrm{mol}^{-1}$ and $-45.3 \sim-39.9 \mathrm{cal} \cdot \mathrm{mol}^{-1} \cdot \mathrm{K}^{-1}$, respectively. The large negative entropies of activation observed for $\mathbf{1}$ in the four solvents are consistent with the bimolecular nature of the rate-determining step. The mechanism for the solvolysis of $\mathbf{1}$ is similar to that reported for the solvolyses of $\mathbf{3 , 4 , 5 , 6}$ and $\mathbf{7}$ in several solvents, which have been suggested to proceed through a bimolecular pathway [16-20].

The extended G-W Equation 1 gives information which is very helpful in assessing the mechanism of solvolysis reactions. Therefore a correlation analysis of the specific rates for the solvolysis of $\mathbf{1}$ was carried out using the extended G-W equation 1 and the $l$ and $m$ values were compared with those previously obtained from the solvolyses of other alkyl haloformates (Table 3) [13,16-22]. As shown in Figure 2, inspection of the plot corresponding to this correlation showed that the four data points for solvolyses in TFE-ethanol mixtures show moderate to appreciable deviation from the linear plot. This was previously discussed in detail using the extended G-W Equation 1 to the specific rates of solvolysis of alkyl and acyl haloformate esters in binary TFE-ethanol solvents [14,22,35,36] and will not be considered again in this report. Correlations were carried out both with and without the TFE-ethanol data, and analysis of the data obtained applying the extended G-W equation 1 to the specific rates of solvolysis of 1 in all the solvents led to an acceptable linear correlation with values of $1.78 \pm 0.13$ for $l$, $0.85 \pm 0.10$ for $m,-0.07 \pm 0.10$ for $c$, and 0.956 for the correlation coefficient. Recalculation with omission of these TFE-ethanol mixture data led to a very good linear correlation with values of $1.68 \pm 0.07$ for $l, 0.80 \pm 0.04$ for $m, 0.01 \pm 0.05$ for $c$, and 0.989 for the correlation coefficient.

The relative magnitudes of $l$ and $m$ ( $l / m$ ratio) have often been suggested to be useful mechanistic criteria. As shown in Table 3, the $l / m$ ratio clearly is divided into two classes with values of 1.8 2.8 for those entries postulated to be associated with the addition-elimination (A-E, Equation 2) mechanism and values of $0.54 \sim 0.84$ for those believed to be associated with the ionization (I, Equations 3 and 4) mechanism. Table 3 shows that the $l$ and $m$ values of $\mathbf{1}$ are similar to those previously reported for other primary and secondary alkyl fluoroformates, e.g., a plot of $\log \left(k / k_{\mathrm{o}}\right)$ for $\mathbf{1}$ against $\log \left(k / k_{\mathrm{o}}\right)$ for $\mathbf{6}$ shows a good linear correlation [i.e., $\left.\log \left(k / k_{\mathrm{o}}\right)_{\mathrm{i} \text {-butyl }}=0.98 \log \left(k / k_{\mathrm{o}}\right)_{\mathrm{n} \text {-octyl }}+0.09, \mathrm{R}=0.990\right]$ in pure and mixed solvents. A good linear relationship for the solvolyses of $\mathbf{1}$ and $\mathbf{6}$ provides strong evidence for a similarity model. The higher $m$-value for the solvolyses of $\mathbf{1}$, relative to $\mathbf{2}$, may reflect the kinetically favorable influence of increased solvation of the developing negative charge on the carbonyl oxygen in the presence of the more electronegative fluorine attached at the carbonyl carbon [16-20,37,38]. As shown in Table 3, the solvolyses of primary and secondary alkyl fluoroformates [methyl (3), ethyl (4), $n$-propyl (5), $n$-octyl (6), $i$-butyl (1) and $i$-propyl (7)] in all the solvents studied were found to proceed through only an addition-elimination mechanism with the addition step being rate-determining (Equation 2), despite the increasing chain length in primary alkyl fluoroformates $(\mathbf{1}, \mathbf{3}, \mathbf{4}, \mathbf{5}$ and $\mathbf{6})$ and the influence of a branched-chain alkyl group as in $\mathbf{7}$. 
Figure 2. Plot of $\log \left(k / k_{o}\right)$ for solvolyses of isobutyl fluoroformate (1) at $40.0{ }^{\circ} \mathrm{C}$ against $\left(1.68 N_{\mathrm{T}}+0.80 Y_{\mathrm{Cl}}\right)$. The $\log \left(k / k_{o}\right)$ values for the four TFE-EtOH mixtures are not included in the correlation; they are added to show their moderate deviation from the correlation line.

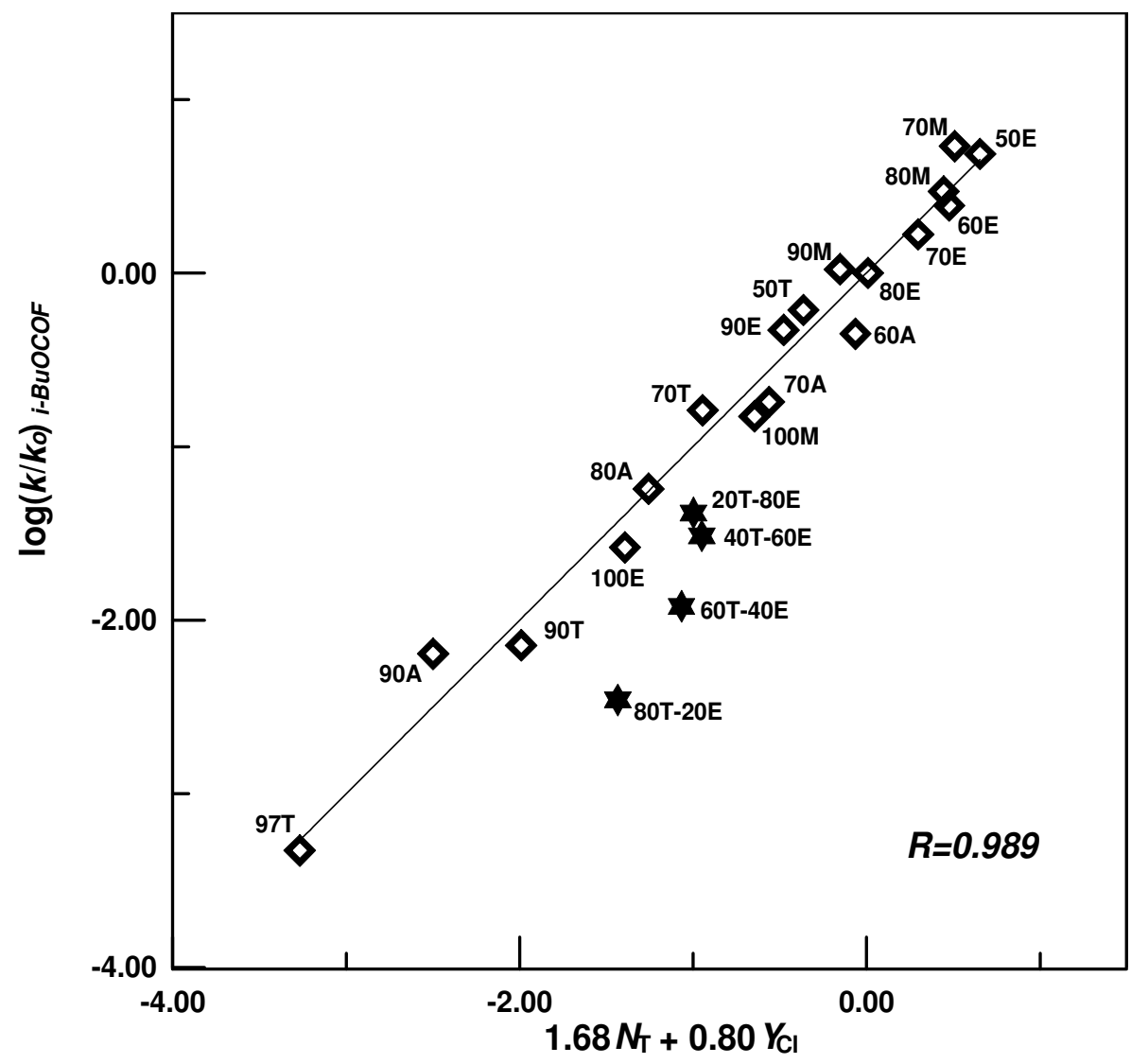

\section{Experimental Section}

Isobutyl chloroformate (2, Aldrich, $21.06 \mathrm{~g}, 0.154 \mathrm{~mol})$ was syringed into a three-neck flask containing dried KF $(11.5 \mathrm{~g}, 0.198 \mathrm{~mol})$ and 18-crown-6 $(1.44 \mathrm{~g}, 0.0054 \mathrm{~mol})$ and fitted with a teflon stirring bar, a condenser topped by an $\mathrm{N}_{2}$ gas inlet, a septum cap, and a ground glass stopper, as described previously [20,39]. The mixture was stirred efficiently at room temperature until IR analysis of an aliquot indicated that no chloroformate remained $\left(\mathrm{C}=\mathrm{O}\right.$ stretch at $1779 \mathrm{~cm}^{-1}$; fluoroformate $\mathrm{C}=\mathrm{O}$ stretch at $1830 \mathrm{~cm}^{-1}$ ). After a few more hours (total reaction time $45 \mathrm{~h}$ ), isobutyl fluoroformate (1) was isolated directly from the reaction apparatus by simple distillation: yield $17 \mathrm{~g}(92 \%)$; b.p. $90-92{ }^{\circ} \mathrm{C}$ at atmospheric pressure (b.p. $92-93{ }^{\circ} \mathrm{C}$ at atmospheric pressure [40]).

Solvents used in solvolysis experiments were purified as previously described [13]. All runs were performed using a substrate concentration of $5.81 \times 10^{-3} \mathrm{~mol} \mathrm{dm}^{-3}$, and $5 \mathrm{~mL}$ portions were removed for titration, except for runs in TFE-H2O and TFE-EtOH mixtures in which $2 \mathrm{~mL}$ portions were used for titrations. Due to the faster rates for the solvolysis of 1 in $50 \% \mathrm{EtOH}$ and $70 \% \mathrm{MeOH}$ than in other solvents, these kinetic measurements were made conductometrically using a Metrohm 712 (Swiss), with an immersion measuring cell (Pt 100). Runs were carried out in duplicate with for each run at least 95 readings for conductivity measurements and eight to ten readings for titration measurements, with infinity readings after ten half-lives. All the integrated specific rate values obtained from each run 
for a given solvolysis were used to calculate an overall average value and the associated standard deviation. The 1 and $\mathrm{m}$ values were calculated using multiple regression analysis.

\section{Conclusions}

The solvolyses of $\mathbf{1}$ give a satisfactory extended Grunwald-Winstein correlation over a wide range of $N_{\mathrm{T}}$ and $Y_{\mathrm{Cl}}$ values. The sensitivities to changes in $N_{\mathrm{T}}$ and $Y_{\mathrm{Cl}}(l=1.68$ and $m=0.80)$ are similar to those for several alkyl fluoroformates, which are shown to solvolyze by an addition-elimination pathway with the addition step being rate determining. The $k_{\mathrm{F}} / k_{\mathrm{Cl}}$ values obtained in a comparison with the corresponding solvolysis of $\mathbf{2}$ are similar to those for the solvolyses of $\mathbf{3}, \mathbf{4}, \mathbf{5}, \mathbf{6}$, and $\mathbf{7}$, consistent with a bimolecular addition-elimination mechanism, proceeding through a tetrahedral intermediate. The solvent deuterium isotope effect value $\left(k_{\mathrm{MeOH}} / k_{\mathrm{MeOD}}=3.40\right)$ for methanolysis of 1 is of a magnitude usually taken to indicate that nucleophilic attack by a methanol molecule is assisted by general-base catalysis by a second methanol molecule. The large negative entropies of activation $\left(-45.3 \sim-39.9 \mathrm{cal} \cdot \mathrm{mol}^{-1} \cdot \mathrm{K}^{-1}\right)$ observed for the solvolyses of $\mathbf{1}$ in four solvents are consistent with the bimolecular nature of the ratedetermining step. In the present study, unlike the solvolyses of $\mathbf{2}$, where two reaction channels were observed (i.e., the addition-elimination pathway, Equation 2 and the ionization pathway, Equation 4), the solvolyses of $\mathbf{1}$ proceed through only an addition-elimination pathway (Equation 2) with the addition step being rate-determining.

\section{References}

1. Grunwald, E.; Winstein, S. The correlation of solvolysis rates. J. Am. Chem. Soc. 1948, 70, 846-854.

2. Grunwald, E.; Winstein, S.; Jones, H.W. The correlation of solvolyses rates and the classification of solvolysis reactions into mechanistic categories. J. Am. Chem. Soc. 1951, 73, 2700-2707.

3. Kevill, D.N.; Anderson, S.W. An improved scale of solvent nucleophlicitiy based on the solvolysis of the $S$-methyldibenzothiophenium ion. J. Org. Chem. 1991, 56, 1845-1850.

4. Kevill, D.N. Development and Uses of Scales of Solvent Nucleophlicity. In Advances in Quantitative Structure-Property Relationship; Charton, M., Ed.; JAI Press: Greenwich, CT, USA, 1996; Volume 1, pp. 81-115.

5. Bentley, T.W.; Carter, G.E. The $S_{N} 2-S_{N} 1$ Spectrum. 4. The $S_{N} 2$ (intermediate) mechanism for solvolyses of tert-butyl chloride: A revised Y scale of solvent ionizing power based on solvolyses of 1-adamantyl chloride. J. Am. Chem. Soc. 1982, 104, 5741-5747.

6. Bentley, T.W.; Llewellyn, G. $Y_{X}$ scales of solvent ionizing power. Prog. Phys. Org. Chem. 1990, 17, 121-158.

7. Kevill, D.N.; D'Souza, M.J. Additional $Y_{\mathrm{Cl}}$ values and the correlation of the specific rates of solvolysis of tert-butyl chloride in terms of $N_{\mathrm{T}}$ and $Y_{\mathrm{Cl}}$ scales. J. Chem. Res. Synop. 1993, 174-175.

8. Von Schleyer, P.R.; Nicholas, R.D. The reactivity of bridgehead compounds of adamantane. J. Am. Chem. Soc. 1961, 83, 2700-2707.

9. Fainberg, A.H.; Winstein, S.J. Correlation of solvolysis rates. III. $t$-Butyl chloride in a wide range of solvent mixtures. J. Am. Chem. Soc. 1956, 78, 2770-2777. 
10. Kevill, D.N.; Kim, J.C.; Kyong, J.B. Correlation of the rates of solvolysis of methyl chloroformate with solvent properties. J. Chem. Res. Synop. 1999, 150-151.

11. Kevill, D.N.; D'Souza, M.J. Concerning the two reaction channels for the solvolyses of ethyl chloroformate and ethyl chlorothioformate. J. Org. Chem. 1998, 63, 2120-2124.

12. Kyong, J.B.; Won, H.; Kevill, D.N. Application of the the extended grunwald-winstein equation to solvolyses of $n$-propyl chloroformate. Int. J. Mol. Sci. 2005, 6, 87-96.

13. D’Souza, M.J.; McAneny, M.J.; Kevill, D.N.; Kyong, J.B.; Choi, S.H. Kinetic evaluation of the solvolysis of isobutyl chloro- and chlorothioformate esters. Beilstein J. Org. Chem. 2011, 7, 543-552.

14. Kyong, J.B.; Kim, Y.G.; Kim, D.K.; Kevill, D.N. Dual pathways in the solvolyses of isopropyl chloroformate. Bull. Korean Chem. Soc. 2000, 21, 662-664.

15. Kevill, D.N.; Kyong, J.B.; Weitl, F.L. Solvolysis-decomposition of 1-adamantyl chloroformate: Evidence for ion pair return in 1-adamantyl chloride solvolysis. J. Org. Chem. 1990, 55, 4304-4311.

16. Seong, M.H.; Choi, S.H.; Lee, Y.W.; Kyong, J.B.; Kim, D.K.; Kevill, D.N. Correlation of the rates of solvolysis of methyl fluoroformate using the extended grunwald-winstein equation. Bull. Korean Chem. Soc. 2009, 30, 2408-2412.

17. Seong, M.H.; Kyong, J.B.; Lee, Y.H.; Kevill, D.N. Correlation of the specific rates of solvolysis of ethyl fluoroformate using the extended grunwald-winstein equation. Int. J. Mol. Sci. 2009, 10, 929-941.

18. Seong, M.H.; Kyong, J.B.; Kim. D.K.; Kevill, D.N. Application of the the extended grunwald-winstein equation to solvolyses of $n$-propyl fluoroformate and a consideration of leaving group effects. Bull. Korean Chem. Soc. 2008, 29, 1747-1751.

19. Kevill, D.N.; D'Souza, M.J. Correlation of the rates of solvolysis of $n$-octyl fluoroformate and a comparison with $n$-octyl chloroformate solvolysis. J. Chem. Soc. Perkin Trans. 2002, 2, 240-243.

20. Lee, S.H.; Rhu, C.J.; Kyong, J.B.; Kim, D.K.; Kevill, D.N. Correlation of the rates of solvolysis of isopropyl fluoroformate using the extended grunwald-winstein equation. Bull. Korean Chem. Soc. 2007, 28, 657-661.

21. Lee, Y.W.; Seong, M.H.; Kyong, J.B.; Kevill, D.N. Correlation of the specific rates of solvolysis of $t$-butyl fluoroformate using the extended grunwald-winstein equation. Bull. Korean Chem. Soc. 2010, 31, 3366-3370.

22. Kevill, D.N.; Kyong, J.B. Multiple pathways in the solvolysis of 1-adamantyl fluoroformate. J. Org. Chem. 1992, 57, 258-265.

23. Kevill, D.N.; Lin, G.M.L. Solvent nucleophilicity. A scale based on triethyloxonium ion solvolysis. J. Am. Chem. Soc. 1979, 101, 3916-3919.

24. Kevill, D.N.; D'Souza, M.J. Use of the simple and extended grunwald-winstein equations in the correlation of the rates of solvolysis of highly hindered tertiary alkyl derivatives. Curr. Org. Chem. 2010, 14, 1037-1049.

25. Sykes, P. A Guidebook to Mechanism in Organic Chemistry, 6th ed.; John Wiley \& Sons: New York, NY, USA, 1986.

26. Kevill, D.N. The Chemistry of the Functional Groups: The Chemistry of Acyl Halides; Patai, S., Ed.; John Wiley \& Sons: New York, NY, USA, 1972. 
27. Swain, C.G.; Scott, C.B. Rates of solvolysis of some alkyl fluorides and chlorides. J. Am. Chem. Soc. 1953, 75, 246-248.

28. Queen, A.; Nour, T.A. Kinetics and mechanism of the acetate catalyzed hydrolysis of 4-methoxyphenyl chloroformate and 4-methoxyphenyl fluoroformate in aqueous dioxane. J. Chem. Soc. Perkin Trans. 1976, 2, 935-939.

29. Koo, I.S.; Yang, K.; Kang, D.H.; Park, H.J.; Kang, K.; Lee, I. Transition-state variation in the solvolyses of phenyl chlorothionoformate in alcohol-water mixtures. Bull. Korean Chem. Soc. 1999, 20, 577-580.

30. Ryu, Z.H.; Shin, S.H.; Lee, J.P.; Lim, G.T.; Bentley, T.W. Kinetics solvent isotope effects and correlations of rates of solvolyses for $\alpha$-methylthio and other substitued acetyl chlorides. J. Chem. Soc. Perkin Trans. 2002, 2, 1283-1287.

31. Oh, Y.H.; Jang, G.G.; Lim, G.T.; Ryu, Z.H. Marked difference in solvation effects and mechanism between solvolyses of substituted acetyl chloride with alkyl groups and with aromatic rings in aqueous fluorinated alcohol and in 2,2,2-trifluoroethanol-ethanol solvent systems. Bull. Korean Chem. Soc. 2002, 23, 1083-1096.

32. Kyong, J.B.; Park, B.C.; Kim, C.B.; Kevill, D.N. Rate and product studies with benzyl and p-nitrobenzyl chloroformates under sovolytic conditions. J. Org. Chem. 2000, 65, 8051-8058.

33. Kyong, J.B.; Ryu, S.H.; Kevill, D.N. Rate and product studies of the solvolyses of benzyl fluoroformate. Int. J. Mol. Sci. 2006, 7, 186-196.

34. Queen, A. Kinetics of the hydrolysis of acyl chlorides in pure water. Can. J. Chem. 1967, 45, 1619-1629.

35. Park, K.H.; Kyong, J.B.; Kevill, D.N. Nucleophilic substution reactions of p-nitrobenzyl chloroformate. Bull. Korean Chem. Soc. 2000, 21, 1267-1270.

36. Kevill, D.N.; Miller, B. Application of the NT solvent nucleophilicity scale to attack at phosphorus: Solvolyses of $N, N, N^{\prime}, N^{\prime}$-tetramethyldiamidophosphorochloridate. J. Org. Chem. 2002, 67, 7399-7406.

37. Kevill, D.N.; D'Souza, M.J. Correlation of the rates of solvolysis of benzoyl fluoride and a consideration of leaving-group effects. J. Org. Chem. 2004, 69, 7044-7050.

38. Kyong, J.B.; Rhu, C.J.; Kim, Y.G.; Kevill, D.N. Rate and product studies with 2-adamantyl fluoroformate under solvolytic conditions. J. Phys. Org. Chem. 2007, 20, 525-531.

39. Anh, D.V.; Olofson, R.A.; Wolf, P.R.; Piteau, M.D.; Senet, J.P.G. A simple conversion of 1-chloroethyl carbonates to fluoroformates: Value in the preparation of tertiary alkyl fluoroformates. J. Org. Chem. 1990, 55, 1847-1851.

40. Cuomo, J.; Olofson, R.A. Efficient and convenient synthesis of fluoroformates and carbamoyl fluorides. J. Org. Chem. 1979, 44, 1016-1017.

(C) 2011 by the authors; licensee MDPI, Basel, Switzerland. This article is an open access article distributed under the terms and conditions of the Creative Commons Attribution license (http://creativecommons.org/licenses/by/3.0/). 